\title{
DEVELOPMENT AND EVALUATION OF NANOSPONGE LOADED TOPICAL HERBAL GEL OF WRIGHTIA TINCTORIA
}

\author{
PADMINI IRIVENTI*, N. VISHAL GUPTA
}

Department of Pharmaceutics, JSS College of Pharmacy, Sri Shivarathreeshwara Nagara, Mysuru, JSS Academy of Higher Education and Research, JSS Medical Institutions Campus, Sri Shivarathreeshwara Nagara, Mysuru 570015, Karnataka, India

Email: paddhu.iriventi@gmail.com

Received: 05 Dec 2018, Revised and Accepted: 19 Oct 2019

\section{ABSTRACT}

Objective: Psoriasis is the most common chronic autoimmune disease. The main objective of the present study was to develop Nanosponge (NS) based Topical gels of Wrightia tinctoria extract using cross-linker and polymer by melting method. It is used in treating Psoriasis.

Methods: Phytoconstituents present in the herbal extract were identified by Liquid Chromatography-Mass Spectroscopy (LC-MS) studies. In vitro drug release and Entrapment Efficiency of all NS were determined. The optimized NS were incorporated in the gel to formulate nano topical gel. Evaluation studies like homogenicity, viscosity, spreadability, $\mathrm{pH}$ and In vitro studies were carried out for all gel formulations.

Results: The prepared gels were transparent, had good viscosity and spreadability. SEM photographs confirmed that the prepared formulation were roughly spherical and porous in nature. In vitro diffusion studies showed drug release of $92.15 \%$ in $24 \mathrm{~h}$.

Conclusion: From this study it can be concluded that constituents responsible for treating psoriasis are present in the obtained extract and prepared NS based topical gel has significant effect in providing sustained drug release.

Keywords: LC-MS, Nanosponges, Olibanum gum, Psoriasis, Topical gel, Wrightia tinctoria

(c) 2020 The Authors. Published by Innovare Academic Sciences Pvt Ltd. This is an open access article under the CC BY license (http://creativecommons.org/licenses/by/4.0/) DOI: http://dx.doi.org/10.22159/ijap.2020v12i1.31198. Journal homepage: https://innovareacademics.in/journals/index.php/ijap

\section{INTRODUCTION}

Psoriasis is a skin disease which is distinguished by massive proliferation, thick inflammatory cell infiltrates, generation of new blood vessels, modifications in lymphatic structure and impaired differentiation of epidermis. It is an autoimmune disorder where environment and genetic components have a Dimethylformamide function. The immune system releases proinflammatory cytokines and growth factors that accelerate the growth of skin cells which accumulate and form thick red patches of skin on various parts of the body [1-3].

Nanoparticles are the colloidal systems with particle size varying from $10 \mathrm{~nm}$ to $1000 \mathrm{~nm}$. These are nano or sub-nano-sized structures which are made of synthetic or semi-synthetic polymers. Nanoparticles of plant medicine are gaining a lot of attention currently. Different types of nanoparticles are Polymeric nanoparticles, Solid lipid nanoparticles, Liposomes, Proliposomes, Niosomes, Liquid crystalline systems, Quantum dots etc. But all these nanoparticles have certain disadvantages like drug loading, toxicity etc [2].

Nanosponges (NS) can conquer these problems. They solubilize poorly water-soluble drug and provide prolonged release as well as improves drugs bioavailability. They can load both hydrophilic and hydrophobic drug molecules because of their inner hydrophobic cavities and external hydrophilic branching. They can move in the body until they come across the exact target site and attach on the surface and start releasing the drug in a controlled manner $[5,6]$.

In preparation of NS cyclodextrins are the most preferable polymer because these are having more capacity to increase the solubility of poorly soluble drugs when compared to other polymers. Cyclodextrins are nanometric biomaterials with a close relationship between molecular status and supramolecular properties. They are a class of cyclic glucopyranose oligomers and are synthesised by enzymatic action on hydrolysed starch [7].

For delivery of NS, topical gels are very attractive drug delivery systems. In-gel preparation usually synthetic and semi-synthetic polymers are used which are expensive and less biocompatible. Plant products serves as alternative to synthetic products because of local accessibility, environmentally friendly nature, lower prices and non-toxic compared to imported synthetic products. Olibanum gum which can be used as a natural polymer in gel preparation, is a dried, gummy exudation obtained from Boswellia serrate (family: Burseraceae). Gum Olibanum is used as an anti-inflammatory remedy. It controls the drug release rate from the dosage form and thus acts as a sustained release polymer [8].

In the present study, NS of Wrightia tinctoria are prepared which are delivered by incorporating into gel. Wrightia tinctoria (Pale indigo) belongs to the family Apocynaceae. Methanolic extract of seeds is used. The most important bioactive principles in seeds are Quercitin, Lupeol, $\alpha$-amyrin, $\beta$-amyrin, wrightial and $\beta$-sitosterol. Different activities exhibited by this plant are wound healing, anti-bacterial, antifungal, anti-inflammatory, antiviral, anti-cancer, anti-diabetic, anti-ulcer, antipsoriatic $[9,10]$.

This research study states that Wrightia extract along with Olibanum gum as a polymer in the form of NS gives sustained release of drugs and exhibits promising antipsoriatic activity. The novelty of this work is this combination of drug and polymer has not been reported till date.

\section{MATERIALS AND METHODS}

Wrightia tinctoria extract was obtained from Sri Nidhi Industries, Mysuru, India. Olibanum gum was bought from Govinda Raj Shetty stores, Mysuru, India. $\beta$-CD was obtained from Himedia, Mumbai, India. Dimethyl carbonate and carbopol were taken from Loba Chemie Mumbai. All other reagents used were of analytical grade.

\section{Phytochemical analysis}

\section{Qualitative analysis of phytochemicals}

Preliminary phytochemical screening was performed for herbal extract. Presence of various phytochemicals was tested [9-11].

\section{Identification of phytoconstituents in extracts using LC-MS studies}

The herbal extract was analyzed by LC-MS method in order to identify different constituents present in them. Specifications of the instrument used in the study were as below: $[8,11,12]$. 


\section{Specifications}

LC column: ACQUITY UPLC BEH C18 $1.7 \mu \mathrm{m}$, Solvent selection A: $0.1 \%$ Formic acid in water, B: Acetonitrile, Mobile Phase: Water: Methanol, Ionization Mode: ES+, Mode: Positive, Injection Volume: 2 microlitre, Column Dimension: $25 \mathrm{~cm} \times 2.5 \mathrm{~mm}$, Mass range: 50 , 1500Software: 1.40 .2532 .

\section{Experimental methods}

\section{Synthesis of drug-loaded NS by melting method}

Three formulations of NS containing $\beta$-cyclodextrin and Dimethyl carbonate (Cross linker) in 1:2, 1:4, and 1:8 ratios were prepared as shown in table 1. Calculated amount of $\beta$-cyclodextrin was dissolved completely in Dimethyl formamide (DMF) in a round bottom flask. Dimethyl carbonate (DMC) was added and the solution was allowed react for $4 \mathrm{~h}$ at $100{ }^{\circ} \mathrm{C}$. This mixture was ground in a mortar and extracted with water and ethanol in order to remove impurities and unreacted DMC. After purification, $100 \mathrm{mg}$ of prepared NS were mixed with water and sonicated for $1 \mathrm{~h}$ in order to avoid aggregates. The sample was dried thoroughly. Into this aqueous suspension of NS $100 \mathrm{mg}$ drug was dispersed. This suspension was stirred constantly at $2000 \mathrm{rpm}$ for $24 \mathrm{~h}$ and complexes were obtained. After complexation, the undissolved drug was separated by centrifugation [13-15].

Table 1: Preparation of NS in different ratio

\begin{tabular}{llll}
\hline S. No. & Formulation & Drug (g) & Polymer: cross linker \\
\hline 1. & NS1 & 1 & $1: 2$ \\
2. & NS2 & 1 & $1: 4$ \\
3. & NS3 & 1 & $1: 8$ \\
\hline
\end{tabular}

\section{Preparation of NS loaded the topical gel}

Measured amount of carbopol 934 was soaked in water (around 5 $\mathrm{ml}$ ) for $2 \mathrm{~h}$. It was then neutralized with triethanolamine (TEA) with stirring. Olibanum gum and drug loaded NS of particular amount were dissolved in pre weighed and an appropriate amount of propylene glycol. This was transferred to carbopol container and mixed further for $20 \mathrm{~min}$. The dispersion was kept aside for 60 min for hydrating and swelling. All the samples were allowed to equilibrate for at least $24 \mathrm{~h}$ at room temperature prior to performing viscosity studies. Table 2 represents various formulations prepared [16].

Table 2: Composition of different formulations

\begin{tabular}{|c|c|c|c|c|c|c|c|}
\hline Formulation & Drug (g) & $\begin{array}{l}\text { Carbapol-934 } \\
(\%)\end{array}$ & Olibanum gum (\%) & Propylene glycol (ml) & TEA(ml) & Propyl paraben (ml) & Water (ml) \\
\hline F1 & 1 & 0.2 & 0.5 & 3 & 0.5 & 0.2 & Q.S \\
\hline $\mathrm{F} 2$ & 1 & 0.3 & 0.5 & 3 & 0.5 & 0.2 & Q.S \\
\hline F3 & 1 & 0.4 & 0.5 & 3 & 0.5 & 0.2 & Q.S \\
\hline $\mathrm{F} 4$ & 1 & 0.2 & 1 & 3 & 0.5 & 0.2 & Q.S \\
\hline F5 & 1 & 0.3 & 1 & 3 & 0.5 & 0.2 & Q.S \\
\hline F6 & 1 & 0.4 & 1 & 3 & 0.5 & 0.2 & Q.S \\
\hline
\end{tabular}

\section{Evaluation studies of NS}

\section{Entrapment efficiency (EE)}

Accurately weighed quantity of $100 \mathrm{mg}$ NS was dissolved in $7.4 \mathrm{pH}$ buffer and stirred up to $10 \mathrm{~min}$ to break the complex. The solution was filtered and $2 \mathrm{ml}$ was taken from it and diluted up to $10 \mathrm{ml}$ with $7.4 \mathrm{pH}$ buffer. It was kept aside for a few minutes and absorbance was measured by UV-spectrophotometer at $550 \mathrm{~nm}$ [15].

$\mathrm{EE}=$ Actual drug content in NS/Theoretical drug content $\times 100$

\section{In vitro drug diffusion studies (For NS)}

In vitro drug release studies were carried out for all formulations using the dialysis membrane method. The membrane was soaked for $24 \mathrm{~h}$ in $7.4 \mathrm{pH}$ buffer and receptor compartment filled with buffer and kept for stirring on a magnetic stirrer. NS powder equivalent to $100 \mathrm{mg}$ was loaded in membrane. The speed of stirring was kept constant (600 rpm) for $12 \mathrm{~h} .5 \mathrm{ml}$ of drug sample was taken at $1 \mathrm{hr}$ interval and replaced with equal amount of freshly prepared buffer. The drug analysis was done using UV-Spectrophotometer at $550 \mathrm{~nm}$. Drug release amount was calculated [15, 17-19].

Based on the above evaluation results, optimized formulation was chosen and SEM study was performed. This formulation was incorporated into gel and further evaluation studies for nanogel were carried out.

\section{Scanning electron microscopy (SEM)}

The surface morphology of formulations was determined using a scanning electron microscope. Samples were mounted on aluminum mount, using the double-sided adhesive tape and sputtered by gold under vacuum and were scanned at an accelerating voltage of $15 \mathrm{KV}$ before observation [15].

\section{Particle size and zeta potential analysis}

The average particle size distribution and charge of the resulting nanoparticles were determined by dynamic light scattering using C: $\backslash$ Microtrac\FLEX 11.0.0.2 Instruments, United Kingdom. The experiment was performed using clear disposable zeta cell, water as a dispersant which has a refractive index (RI)-1.330 and viscosity (cP)-0.898 and the temperature was kept constant at $25^{\circ} \mathrm{C}$. The optimized NS formulation was further incorporated into topical nanogel prepared.

\section{Evaluation of nanogel}

\section{Determination of $\mathrm{pH}$}

Digital $\mathrm{pH}$ meter was used to determine the $\mathrm{pH}$ of the gels. Glass electrode was completely placed into the gel system [15-17].

\section{Homogenicity}

After placing the gels in the container, all formulations were tested for homogenicity (appearance and presence of any aggregates) by inspecting visually [15-17].

\section{Spreadability test}

$0.5 \mathrm{gm}$ gel was kept on a glass plate in a $1 \mathrm{~cm}$ diameter circle. $0 \mathrm{n}$ this, another glass plate was placed and $500 \mathrm{gm}$ of weight was placed for $5 \mathrm{~min}$ above upper glass plate. Spreadability was calculated. Below formula was used to calculate spreadability [15-17]. 


$$
\mathrm{S}=\mathrm{M} \cdot \mathrm{L} / \mathrm{T}
$$

Where, $\mathrm{S}=$ Spreadability, $\mathrm{M}=$ Weight tide to upper slide, $\mathrm{L}=$ Length of the glass slide, $\mathrm{T}=$ Time taken to separate the glass slide completely from each other.

\section{Rheological studies}

All measurements were carried out by using parallel plates measuring systems having $50 \mathrm{~mm}$ diameter and $1 \mathrm{~mm}$ gap at $25^{\circ} \mathrm{C}$. The rheological properties of the formulated gels and nanogel were studied at different rpm and the viscosity was calculated in Pa S [15-17].

\section{In vitro drug diffusion studies (For gel)}

Nanogels were permeated through an artificial cellophane membrane. $0.5 \mathrm{gm}$ of nanogel was placed in the donor compartment. The receptor medium consists of $\mathrm{pH} 7.4$ phosphate buffer. The temperature was maintained at $37 \pm 0.5{ }^{\circ} \mathrm{C}$ to simulate the human skin condition during the experiment. $5 \mathrm{ml}$ of sample was withdrawn at $0.5,1,2,6,12$ and $24 \mathrm{~h}$ and replaced with fresh receptor solution. Collected samples were spectrophotometrically analyzed at $550 \mathrm{~nm}$. The drug release amount was calculated [18].

\section{Ex vivo permeation study of NS loaded the topical gel}

Animals were purchased from Adita Biosys Private Limited, Tumkur and housed at the institution animal facility. Study was conducted after the approval from the institutional animal's ethics committee, (Proposal No. P12-282/2018). The skin of BALB/c mice was collected and used for ex vivo permeation study.

Nanogel containing pure Wrightia tinctoria extract and nanogel with optimized NS were prepared and permeated through the dorsal skin of mouse. A procedure similar to that in in vitro drug diffusion studies was followed [19].

\section{RESULTS AND DISCUSSION}

\section{Phytochemical analysis}

\section{Qualitative analysis of phytochemicals}

Different phytochemicals present in both the extracts were identified. Results obtained were also given in table 3. From the results, it can be concluded amino acids, alkaloids, flavonoids, tannins, carbohydrates, glycosides, saponins, triterpenoids are present in the extract.

Table 3: Phytochemicals present in methanolic extracts of wrightia

\begin{tabular}{|c|c|c|c|c|}
\hline S. No. & Constituents & Test & Obesrvation & Results \\
\hline 1. & Alkaloids & Mayer's test & Formation of creamy precipitate. & Positive \\
\hline 2. & Flavanoids & Lead acetate test & Formation of yellow precipitate & Positive \\
\hline 3. & Carbohydrates & Molish's test & Formation of violet ring at the junction. & Positive \\
\hline 4. & $\begin{array}{l}\text { Triterpenoids and } \\
\text { steroids }\end{array}$ & Salwonski test & $\begin{array}{l}\text { Presence of steroids is confirmed if the lower layer turns red and that of } \\
\text { triterpenoids by Golden yellow layer at bottom }\end{array}$ & Positive \\
\hline 5. & Deoxy sugars & Killer kiliani's test & Formation of blue color in the acetic acid layer & Positive \\
\hline 6. & Glycosides & Legal's test & Formation of pink to a blood-red color & Positive \\
\hline 7. & Reducing sugars & Benedict's test & $\begin{array}{l}\text { Depending on the amount of reducing sugar present in the test solution appears } \\
\text { green or yellow or red }\end{array}$ & Positive \\
\hline 8. & Amino acids & Ninhydrin's test & Formation of blue color & Positive \\
\hline
\end{tabular}

\section{Identification of phytoconstituents in extracts using LC-MS studies}

Base peak Ionization (BPI) Chromatogram of methanolic Wrightia extract was obtained as shown in fig. 1 , which states that retention time of constituent $\beta$-amyrin (Molecular weight-426.787 $\mathrm{g} / \mathrm{mol}$ ) present in the methanolic extract was around 2.75. Fig. 2 shows the Mass spectrum related to this RT. Similarly, RT of another constituent Quercetin Hexaacetate (Molecular weight $720.721 \mathrm{~g} / \mathrm{mol}$ ) was around 4.42. Its Mass spectrum is shown in fig. 3.

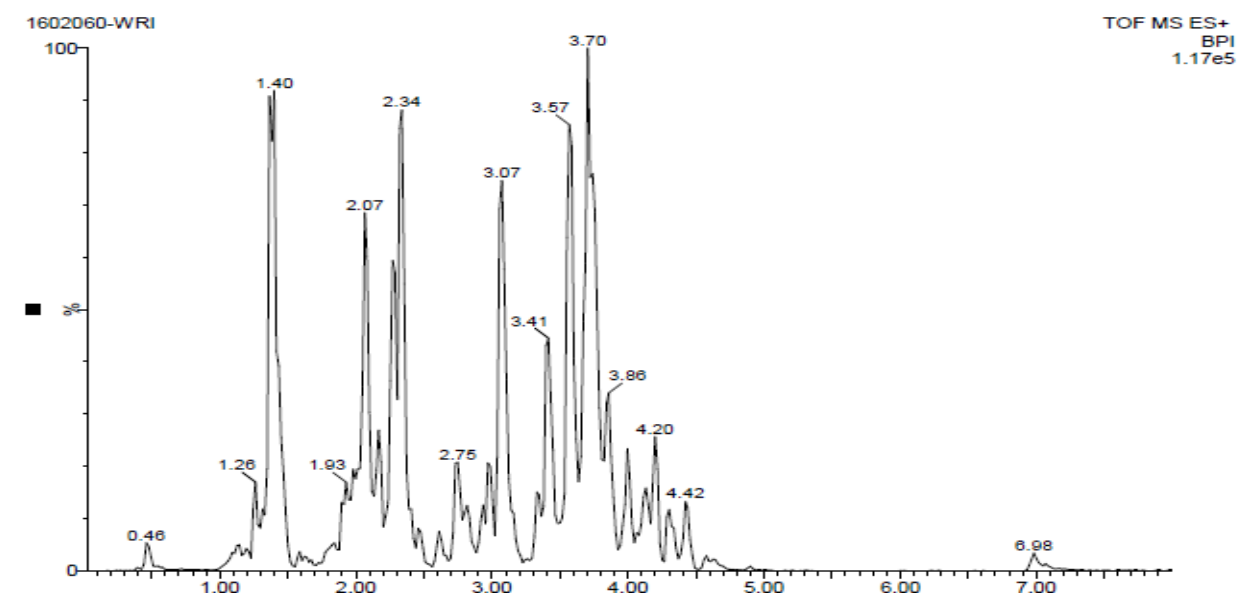

Fig. 1: Base peak ionization (BPI) chromatogram of wrightia

Table 4: Evaluation parameters for nanosponges

\begin{tabular}{llll}
\hline S. No. & Formulation & Entrapment efficiency & In vitro diffusion studies \\
\hline 1. & NS1 & $44.14 \pm 0.050330$ & $83.34 \pm 0.13$ \\
2. & NS2 & $52.28 \pm 0.020816$ & $92.67 \pm 0.24$ \\
3. & NS3 & $47.31 \pm 0.015275$ & $86.21 \pm 0.18$ \\
\hline
\end{tabular}

*mean \pm SD $=$ Standard Deviation from the mean, $n=6$ 
1602060-WRI 160 (2.749)

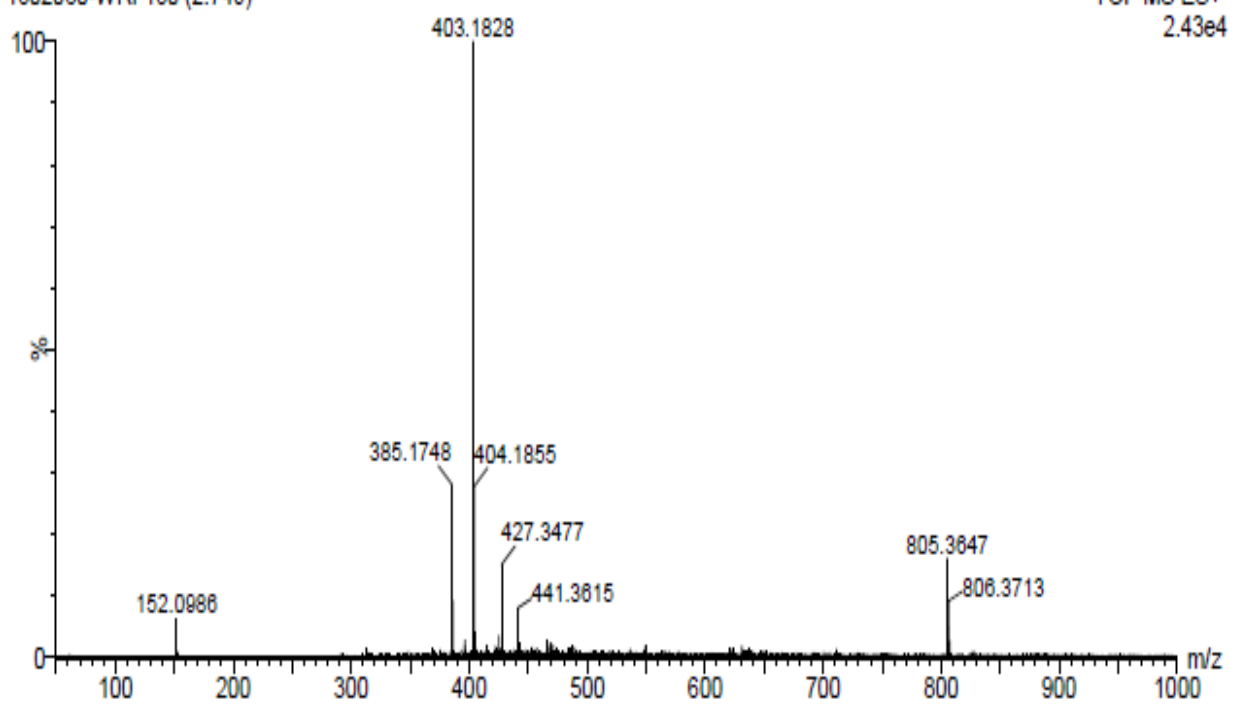

Fig. 2: Mass spectrum of $\beta$-amyrin

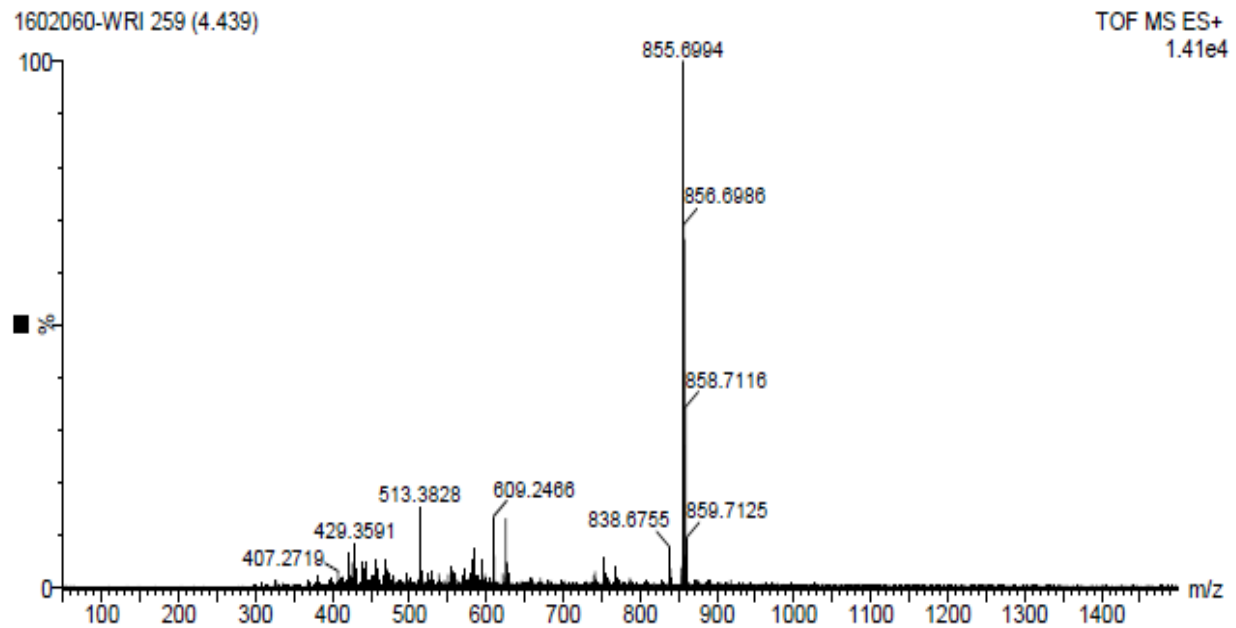

Fig. 3: Mass spectrum of quercetin hexa-acetate

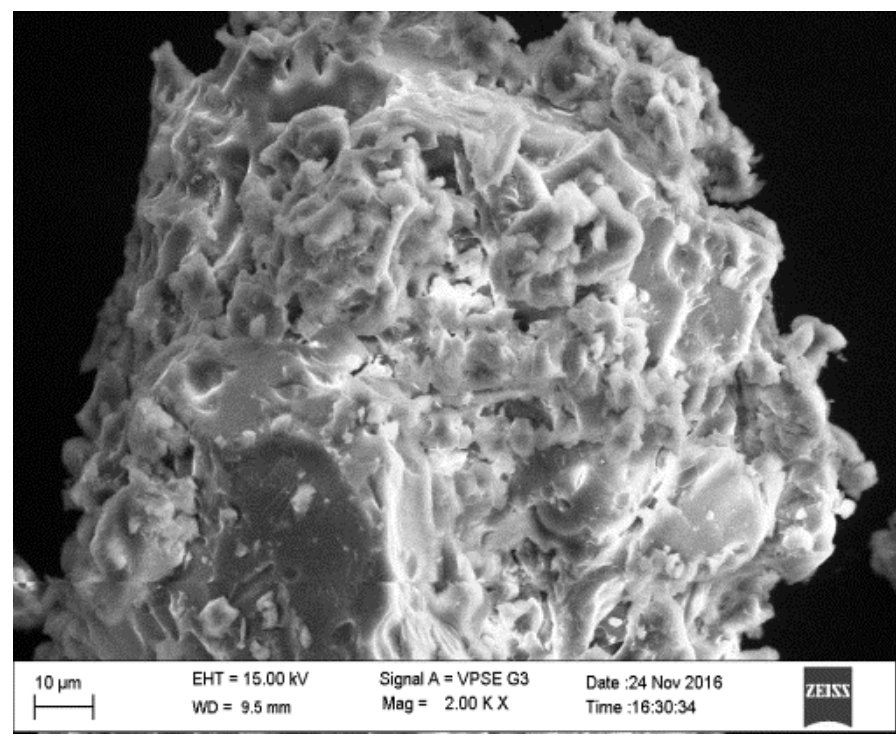

Fig. 4: Scanning electron microscopy (SEM) of NS formulation (NS2) 


\section{Evaluation studies of NS}

Entrapment Efficiency and In vitro dissolution studies were conducted for all formulations prepared by varying the drug: polymer ratio. Results are given in table 4 .

Entrapment efficiency shows the amount of drug entrapped in $\beta$ cyclodextrin. It was calculated for all NS and ranged from $83.34 \%$ to $92.67 \%$. It changes according to the variation in drug: polymer ratio and depends upon the cross-linker used in the formulation. The highest loading efficiency was found for NS2 formulation, where a greater amount of drug was encapsulated. From the encapsulation studies, it was confirmed that the dimethyl carbonate was considered as an efficient cross-linker for the formulation of NS.

\section{Scanning electron microscopy (SEM)}

Scanning electron microscopy for the optimized formulation was performed to check the morphology of nanosponges. The prepared optimized NS (NS2) formulation was roughly irregular in shape and porous in nature. The SEM photograph is shown in fig. 4.

\section{Particle size and zeta potential analysis}

The particle size was measured for optimized formulation NS2 by light scattering method using Zeta sizer. Size of a particle is a very important parameter in NLC performance because drug release rate, extend and drug absorption are majorly affected by it. As the particle size decreases, the interfacial area available for drug diffusion increases and thus improve in drug release can be seen. The Ostwald ripening probability was conquered because of narrow size distribution [20].

The mean diameter of formulation NS2 was around $192.5 \mathrm{~nm}$. Particle distribution was given in fig. 5.

In the interaction of formulation with the biological system, zeta potential plays a significant role and it has been reported in various studies [21]. Zeta potential gives the type of charge present on the surface of the NS. This gives the stability of the prepared formulation. The dividing line between the stable and unstable suspensions was generally taken at $+30 \mathrm{mV}$ or $-30 \mathrm{mV}$, which were considered as the limits for the zeta potential. The zeta potential for the prepared formulation was found to be $21.5 \mathrm{mv}$. This indicates that particles are moderately stable.

\section{Evaluation of nanogel}

Nanogels prepared were evaluated for different parameters and the values were given in table 5. In vitro drug release graph was shown in fig. 6.

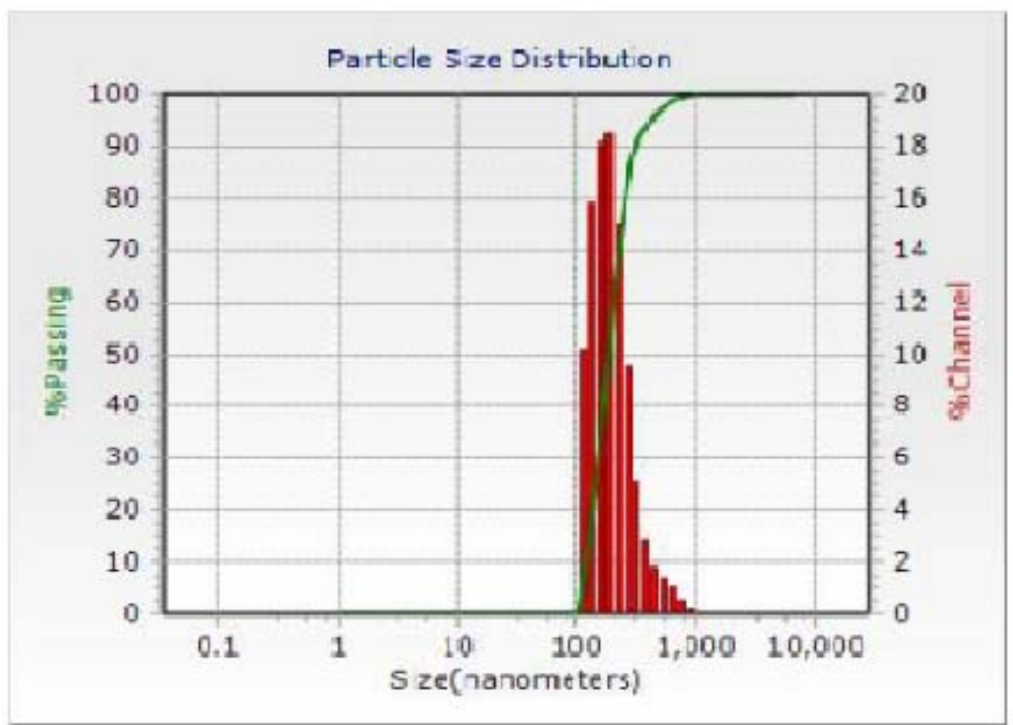

Fig. 5: Particle size distribution of formulation NS2

\section{pH determination}

$\mathrm{pH}$ values of all gels formulations were found to be between 5.2-7.5, which states that the values were within the range near to that of skin $\mathrm{pH}$. An increase in $\mathrm{pH}$ values may lead to skin irritation.

\section{Homogenicity}

All the prepared gels were homogenous and clear without any aggregates.

\section{Spreadability}

Spreadability is inversely proportional to the viscosity of prepared gel. Spreadability decreased as the polmer and carbopol amounts increased. The spreadability of the prepared carbopol gel formulation was in the range of 3.8 to $10.5 \mathrm{gm} / \mathrm{cm}$. These values were represented in table 5 . All the formulations showed good spreadability.

\section{In vitro drug diffusion studies}

The NS formulations were subjected to in vitro release studies. Obtained results shows that F5 formulation containing $0.3 \%$ of carbopol-934 and $1 \%$ of olibanum gum has shown the drug release of $16.18 \%$ in initial $0.5 \mathrm{~h}$ and upto $91.64 \%$ in $24 \mathrm{~h}$. Carbopol 934 when taken in medium amount, provides good viscosity to the gel which further shows good spreadability. An increase or decrease in carbopol percent $(0.2 \%$ and $0.4 \%)$ leads to decreased drug release. Similarly olibanum gum amount when taken in $0.5 \%$ amount gives less drug release. For immediate control of disease symptoms, optimum concentration is provided from initial burst release and concentration required for overall treatment is provided by prolonged drug release. The conclusions drawn from the study were supported by the findings of Joshi et al. [22]. The results obtained in in vitro release studies were plotted as percent cumulative drug release Vs time and shown in fig. 6.

\section{Ex vivo permeation study of NS loaded the topical gel}

The formulation containing pure drug extract has shown drug release for $12 \mathrm{~h}$ and after that no release was noticed; whereas NS formulation gel has shown release till $24 \mathrm{~h}$ (Max 87.15\%).

The results obtained in ex vivo release studies were plotted as percent cumulative drug release Vs time and shown in fig. 7. Since NS gel is a nano formulation, sustained release of drug is noticed and the release time of this formulation was prolonged. 
Table 5: Evaluation parameters for nanogels

\begin{tabular}{llllll}
\hline Formulation & $\mathbf{p H}$ & Homogenicity & Spreadability $\left(\mathbf{g m} / \mathbf{c m}^{\mathbf{2}}\right)$ & Viscosity (Pa. S) & In vitro diffusion studies (\%) \\
\hline F1 & 6.2 & Clear, transparent & $3.82 \pm 0.251$ & 0.581 & 7.482 \\
F2 & 5.9 & Clear, transparent & $4.55 \pm 0.035$ & 2.852 & $78.19 \pm 0.98$ \\
F3 & 5.3 & Clear, transparent & $10.51 \pm 0.036$ & 0.984 & $73.23 \pm 0.93$ \\
F4 & 6.1 & Clear, transparent & $8.64 \pm 0.026$ & 1.913 & $85.22 \pm 1.03$ \\
F5 & 7.5 & Clear, transparent & $5.2 \pm 0.041$ & 2.975 & $91.44 \pm 0.76$ \\
F6 & 5.7 & Clear, transparent & $9.53 \pm 0.025$ & $82.16 \pm 0.94$ \\
\hline
\end{tabular}

*mean \pm SD $=$ Standard Deviation from the mean, $\mathrm{n}=6$

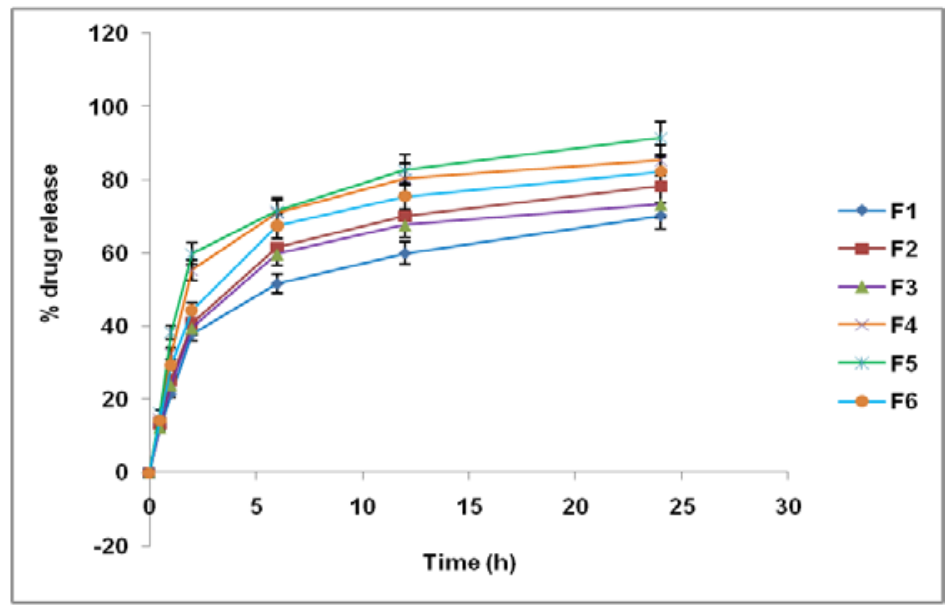

Fig. 6: In vitro drug release studies

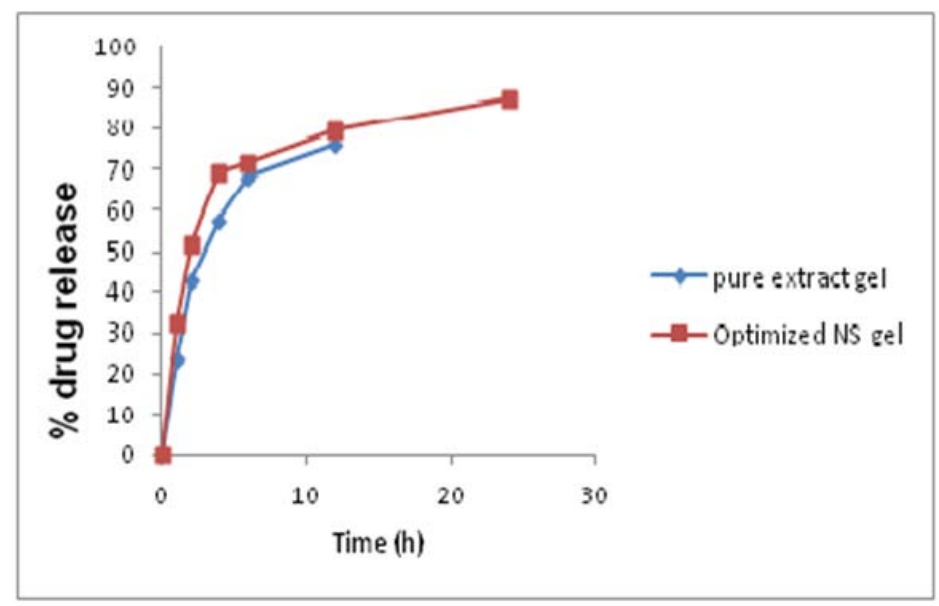

Fig. 7: Ex vivo drug permeation studies

\section{CONCLUSION}

NS were effective vehicles for delivery of Wrightia extract. Olibanum gum, a natural polymer, when used in $1 \%$ amount, has proved to show sustained release activity. From all the above results it was concluded that NS with 1:2 ratio polymer and crosslinker has shown good in vitro release. Olibanum gum and Carbapol-934 in 1\% and $0.3 \%$ respectively exhibited good release activity. Sustained release of Wrightia extract was achieved till $24 \mathrm{~h}$ by delivering in the form of topical nanogel.

\section{ACKNOWLEDGMENT}

The author(s) express the deep sense of gratitude towards JSS Academy of Higher Education and Research (JSSAHER), Mysuru and University of Mysore, Mysuru and for provision of obligatory facilities to carry out present research work.

\section{AUTHORS CONTRIBUTIONS}

All the authors have contributed equally.

\section{CONFLICT OF INTERESTS}

Declared none

\section{REFERENCES}

1. Michelle AL, Anne MB, James GK. Pathogenesis and therapy of psoriasis. Nature 2007;445:866-72.

2. Eman SEL, Amna MM, Abeer MK, Doaa GH. Nanoemulsion gel of nutraceutical co-enzyme $\mathrm{q} 10$ as an alternative to the conventional topical delivery system to enhance skin permeability and anti-wrinkle efficiency. Int J Pharm Pharm Sci 2017;9:207-11.

3. Sanaa EG, Maha F, Basma M, Fatma EZ. Betamethasone dipropionate gel for the treatment of localized plaque psoriasis. Int J Pharm Pharm Sci 2017;9:173-82.

4. Vyas SP, Khar RK. Targeted and controlled drug delivery novel carrier systems. CBS publishers and distributors, N. Delhi; 2002;2:346-8. 
5. Madhuri S, Sunil KP, Alok M, Shashi A, Poonam Y, Amita V. Nanosponges: a potential nanocarrier for novel drug delivery-a review. Asian Pac J Trop Dis 2015;5:23-30.

6. Nikita S, Vishal GN, Sandeep K. A review on nanosponges a review on nanosponges: a boon to targeted drug delivery for an anticancer drug. Asian J Pharm Clin Res 2019;12:1-7.

7. Ashwini D, Pritesh P. Preparation and evaluation of cyclodextrin based Atorvastatin. Am J Pharm Tech Res 2014; 4:570-87

8. Sailaja G, Swathi CK, Darshini SB. Evaluation of release retarding efficiency of olibanum gum-a natural polymer in comparison to known polymers. Int J Pharm Ind Res 2014:4:33-8.

9. Selvakumar S, Sanjeet KS. Preliminary phytochemical screening of wrightia tinctoria. Res J Pharm Bio Chem Sci 2016;7:8-11.

10. Nagalakshmi HS, Arijit D, Sourav B. In vitro antimicrobial properties and phytochemical evaluation of mature seed extracts of wrightia tinctoria. J Pure Appl Microbiol 2012;6:1273-9.

11. Jain PS, Bari SB. Isolation of lupeol, stigmasterol and campesterol from petroleum ether extract of woody stem of wrightia tinctoria. Asian J Plant Sci 2010;9:163-7.

12. Mahendra SK, Nityanand PV. Wrightia tinctoria R. Br.-a review on its ethnobotany, pharmacognosy and pharmacological profile. J Coast Life Med 2014;2:82640.

13. Rajani S. A review on phytochemical, pharmacological, and pharmacognostical profile of Wrightia tinctoria: adulterant of kurchi. Phcog Rev 2014;8:36-4.

14. Khalid AA, Pradeep RV, Francesco T, Roberta C. Cyclodextrinbased nanosponges for delivery of resveratrol: in vitro characterization, stability, cytotoxicity and permeation study. AAPS PharmSciTech 2011;12:279-86.

15. Darandale SS, Vavia PR. Cyclodextrin-based nanosponges of curcumin: formulation and physicochemical characterization. J Incl Phenom Macrocycl Chem 2013;75:315-22.

16. Ansari KA, Pradeep RV, Francesco T, Roberta C. Cyclodextrinbased nanosponges for delivery of resveratrol: in vitro characterization, stability, cytotoxicity and permeation study. AAPS PharmSciTech 2011;12:279-86.

17. Subhash Chandra BP, Nagaraju R, Saritha D, Sailakshmi B, Srikanth R. Formulation and evaluation of lansoprazole loaded nanosponges. Turk J Pharm Sci 2016;13:304-10.

18. Sarfaraz A. Formulation and evaluation of clobetasol propionate loaded nanoemulsion gel containing tea tree oil. World J Pharm Pharm Sci 2016;5:616-28.

19. Phatak AA, Chaudhari PD. Development and evaluation of nanogel as a carried for transdermal delivery of aceclofenac. Asian J Pharm Tech 2012;2:125-32.

20. Chetan GS, Pramod kumar TM, Venkatesh MP. Intra-articular delivery of methotrexate loaded nanostructured lipid carrierbased smart gel for effective treatment of rheumatic diseases. RSC Adv 2016;16:1-43

21. Zhang X, Pan W, Gan L. Preparation of a dispersible PEGylate nanostructured lipid carriers (NLC) loaded with 10-hydroxycamptothecin by spray-drying. Chem Pharm Bull 2008; 56:1645-50.

22. Joshi M, Pathak S, Sharma S, Patravale V. Design and in vivo pharmacodynamic evaluation of nanostructured lipid carriers for parenteral delivery of artemether: nanoject. Int J Pharm 2008;364:119-26 